\title{
Explaining new trends in the gender gap of mortality: Insights from a regional trend- analysis of the Netherlands
}

\author{
Jeroen Spijker, Frans van Poppel, and Leo van Wissen*
}

\begin{abstract}
The recent decrease of the male-female mortality gap in Western Europe has been accompanied by changes in the life style, educational level, family roles and employment of women. In this paper we try to find out whether a relationship indeed exists between the increase in gender equality and the decrease in the male/female mortality difference. We used regional-level data for the Netherlands for the periods 1980-83 and 1996-99 on gender differences in life expectancy, by age group and cause of death, and various measures of gender inequality on the same regional level. In doing this we followed as far as possible a framework recently developed by Ingrid Waldron to analyse changes in gender differences in mortality in the US. The cross-sectional analyses showed that in 1980-83 it was rather socioeconomic than gender role variables that were important in explaining gender difference in mortality, while in the period 1996-99, it was the other way around.
\end{abstract}

\section{Introduction}

Around 1980, many northern and western European countries reached their peak in female-male differences in life expectancy at birth. During the following two decades, these gender differences ${ }^{1}$ started to decline, particularly in Norway,

\footnotetext{
* Jeroen Spijker (author for correspondence), Centre d'Estudis Demogràfics, Universitat Autònoma de Barcelona, 08193 Bellaterra (Barcelona), Spain. Email: jspijker@ced.uab.es Frans van Poppel, Netherlands Interdisciplinary Demographic Institute, The Hague, the Netherlands.

Leo van Wissen, Faculty of Spatial Sciences, University of Groningen, the Netherlands.

1 The term "gender" was preferred above "sex" as changes in female-male differences in mortality do not appear to be due to biological changes but to a convergence or divergence in lifestyle and behaviour. "Gender differences" are operationalised as "female minus male".
} 
Sweden, Denmark, the Netherlands and the UK. Female-male differences in life expectancy at birth dropped in these countries between 1.3 and 2.0 years, i.e., from between 6 and 7 years to between 4 and 5 years (Council of Europe 2003). Several authors have related this narrowing of the gender mortality gap to the significant changes that during the same period occurred in the life style, education, family roles and employment of women (see e.g., Annandale and Hunt 2000 for a review). Nowadays, women are almost as likely as men to be employed, and educational levels have converged with those of men. Changes in employment and education have been accompanied by changes in the family and household situation of women: the number of children per woman has decreased, more women remain childless, childbearing is postponed, marriage rates have decreased, and divorce rates increased. The domestic division of labour has partly adapted to the changes in women's paid employment and as a consequence, gender differences in time spent in housework have decreased.

Although the changes in the role and position of men and women have affected all countries in northern and western Europe, the extent of and the speed in the changes in the position of men and women vary considerably between regions. Changes in the position of women could spread more rapidly in areas that are both culturally and socially receptive to these changes. The geographic variation in, for example, female employment rates, family and household situation and educational level might have led to geographic variation in the size of the mortality gap between men and women. The effect of the changing position of men and women on the gender gap in mortality might empirically be tested by using information about various indicators of the position of men and women for geographical units on one hand and about male/female mortality levels on the other. This can be done by using information on one point in time and by studying changes over time in both the gender and mortality indicators. Examples of studies along these lines include work by Kawachi et al. (1999) at the US state level and Anson (2003) on Belgium municipalities. In our study, we use regional data for the Netherlands to analyse the factors behind the changing male/female mortality gap. We study a period with the highest gender differences in life expectancy (1980-83) and compare that with the period 1996-99, in which gender differences had decreased strongly. In terms of regional mortality differences in the Netherlands, "the geographical variation in mortality is still not negligible" (Mackenbach et al. 1991), although there has been a tendency towards a convergence. We also study the changes between these two cross-sections. To link the changes in the position of women to changes in gender differences in mortality, we take a series of hypotheses formulated by Waldron (2000) as our starting point. These hypotheses particularly relate to gender-specific changes in smoking behaviour, labour force participation, emancipation, and general role modernisation.

In what might be called a "Smoking Hypothesis", Waldron suggested that the trends in gender differences in cigarette smoking have been a major cause of the 
trends in gender differences in mortality. Since the 1980s, in many countries gender differences in smoking have decreased and this is seen as a factor contributing to the decrease in gender differences in mortality due to lung cancer and chronic obstructive pulmonary disease.

A second hypothesis suggests that decreasing gender differences in labour force participation result in decreasing gender differences in mortality. This hypothesis assumes that women who are employed experience increased mortality risks because they are exposed to occupational hazards and job stresses, and are more prone to adopt risky behaviours such as heavy drinking and smoking, due to increased independence and personal income.

A related hypothesis, which Waldron called the Women's Emancipation Hypothesis, proposes that the changes in female roles and a general liberalisation of norms concerning women's behaviour have resulted in decreasing gender differences in health-related behaviour and consequently have decreased gender differences in mortality. Increased participation by women in the labour force is assumed to have had indirect effects on women's health-related behaviour, contributing to a general shift in cultural norms and to a relaxation of restrictions on women's behaviour. A point in case is the decreasing social disapproval of women smoking, consuming alcohol and driving.

A more general hypothesis, the Gender Roles Modernisation Hypothesis, assumes that fundamental aspects of traditional gender roles have interacted with recent changes in socio-economic, cultural and material conditions to influence behavioural trends. To illustrate this hypothesis, Waldron refers to trends in time devoted to housework. Due to decreased childbearing, increased female labour force participation, greater proportions of children living with only their mothers and changes in allocation of time by parents who live with children, the gender differences in time devoted to employment and housework have decreased. Yet there appears to have been little change in gender differences in time devoted to child care, which continues to be seen primarily as the responsibility of women. A second example relates to health behaviour. Women are more likely to adopt health-related behaviours that are seen as compatible with traditional female roles. Thus, since heavy drinking may interfere with a woman's ability to meet traditional female roles in child care and sexual restraint, women are not expected to adopt heavy drinking and therefore gender differences in heavy drinking are not expected to decrease; on the other hand, women's driving serves many functions within the family and thus one might expect to see increases in women's driving and decreases in gender differences in driving. Female road exposure is also likely to augment due to the disruption of traditional values and the ensuing role ambiguity that has allowed women to integrate into the world of work and social life outside the family. This will as a consequence result in convergence over time in male and female deaths in traffic accidents (Pampel 2001). 
The analysis is split into three parts. First, we describe the regional differences in the gender gap in life expectancy for the early 1980s and late 1990s and the age groups and causes of death that were responsible for these differences. Next, we test cross-sectionally for the two periods our assumption that the emancipation of Dutch women in work and social life outside the family has been detrimental to their health. This is done by analysing the association between regional differences in the gender mortality gap and regional differences in genderinequality-related factors that have been selected from the theoretical framework developed by Waldron (2000). We finish our analysis by investigating changes in regional gender differences over time. A map of the regions that are analysed is given in Figure 1.

\section{Figure 1:}

\section{Map of the regions used in the study}

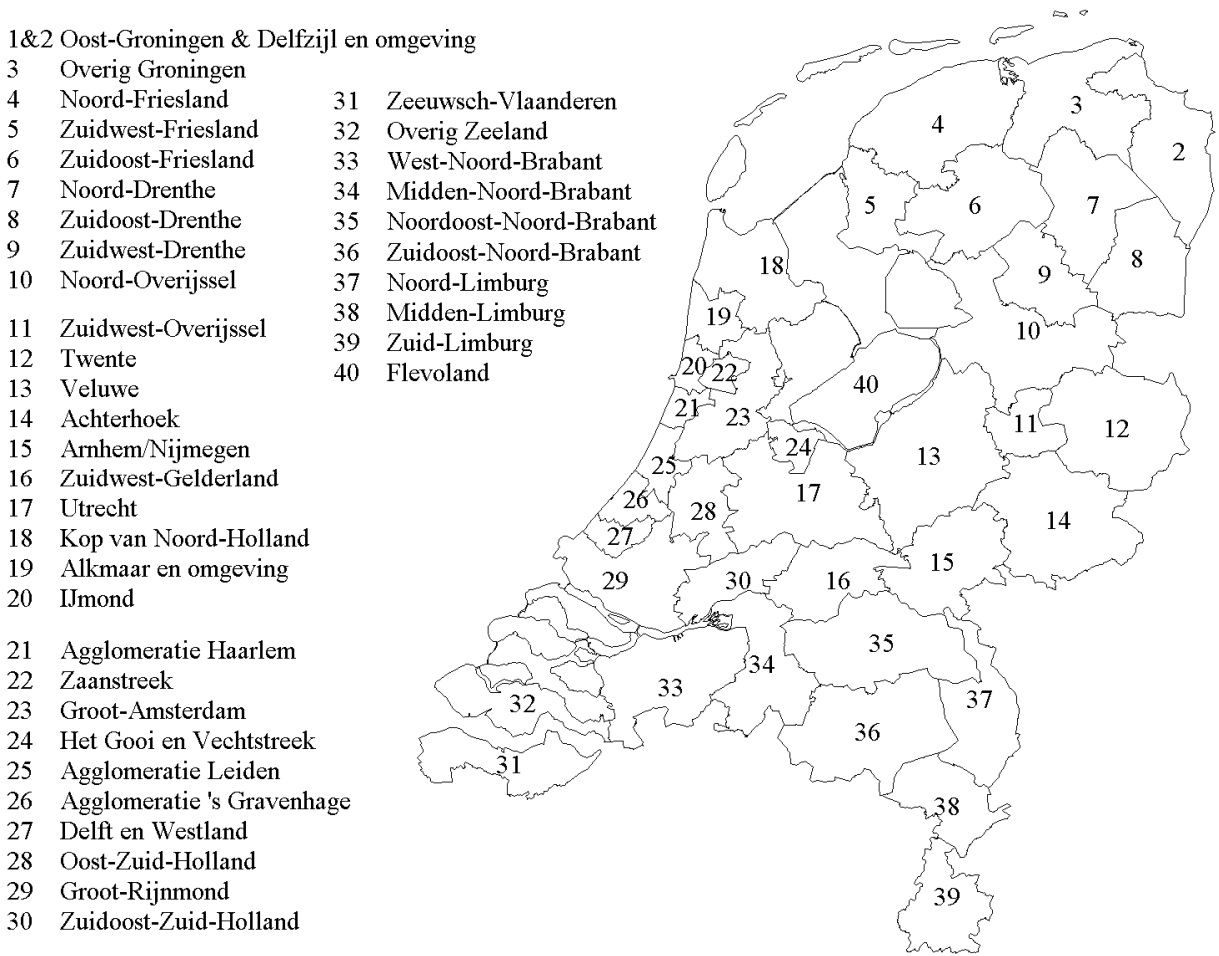




\section{Social-cultural context and regional diversity}

Despite the small size of the country, the Netherlands has historically shown regional diversity in its cultural, social and economic characteristics. Until the 1960s, religion had a prominent position in Dutch society, whereby Catholics, Protestants (Orthodox-Calvinists and Dutch Reformed) and an increasing group without religious affiliation tended to be concentrated in distinct parts of the country (Sobotka and Adigüzel 2002). Each denomination provided a comprehensive institutional framework, with distinct schools, media, political parties and community organisations. This compartmentalisation has shaped the attitudes and regulated the behaviour of its members towards for example sexuality and gender roles that subsequently influenced their socio-demographic behaviour. For instance, the area that stretches from the north to the southwest of the Netherlands contains most of the religious and conservative Protestant municipalities of the so-called "Bible Belt" that throughout most of the 20th century were characterised by higher fertility levels, lower divorce rates and lower mortality than what was average for the country. The Randstad area in the west ${ }^{2}$, the economic and cultural centre of the country which is wealthier, more urbanised and culturally more diverse, is strongly secularised, contains a higher proportion of immigrants, and has lower fertility (Mackenbach et al. 1990; Mackenbach and Kunst 1995; Sobotka and Adigüzel 2002; RPD 1999). The south was until recently predominantly Catholic and poorer, two factors that have been associated with higher mortality in this part of the country since the late 19th century (Van Poppel 1992; Mackenbach et al. 1991).

Regional diversity in the relative position of men and women in the Netherlands also remains present. This applies to a variety of factors that have a potential effect on mortality differences between men and women. Smoking is by far the most important of these. Valkonen and Van Poppel (1997) estimated that in 1970-74 of the 5.2 years that the life expectancy at age 35 differed between men and women, 3.8 years out could be attributed to smoking. In 1985-89 this had declined to 3.2 years, even though the total difference had increased to 6.0 years. Geographic differences in relative smoking levels of men and women clearly exist. For instance, in 1972 male smoking levels were highest in the south and east of the country, while for women the highest levels were found in the west and northwest. The resulting gender differences in smoking were typically lowest north and west of Amsterdam (just 9\% in IJmond in 1972 and 1\% in Amsterdam in 1980) and highest in a zone stretching from the northeast of the country to the southwest (the excess male smoking prevalence in ZeeuwsVlaanderen was $48 \%$ in 1972 and still $35 \%$ in 1980).

This is the name given to a large, almost contiguous, horseshoe-shaped area with a polynuclear structure in the west of the Netherlands. It comprises the agglomeration of the four largest cities (Amsterdam, Rotterdam, The Hague and Utrecht), as well as a number of smaller cities. The 1999 population was about 6 million within an area of approximately $4500 \mathrm{~km}^{2}$. 
The position of women in the labour force showed a greater convergence with men. In 1973 the highest levels of female labour force participation, up to $24 \%$ of the working-age population, were found in the Randstad, compared to less than $15 \%$ in several northern regions. By 1981 this had increased to $39 \%$ and $25 \%$, respectively. As male labour force participation levels only increased slightly during this period (from $68 \%$ to $72 \%$ for the country as a whole), gender differences declined. During the 1980s and 1990s female levels continued to increase quite substantially across the country. As male rates increased on average just by a few percentage points, the ensuing gender differences declined further still. The lowest gender differences in labour force participation are currently found in the larger urban regions of the west, though still with a male excess of at least $15 \%$.

The family position of men and women also changed over time. For instance the increase in the proportion of divorced persons aged 45-74 between the early 1980 s and the late 1990s, affected women more than men. The largest gender discrepancies were found in the Randstad, where absolute levels of divorce were highest during both periods (e.g., in Groot-Amsterdam in 1996-99 17.5\% of the female population aged 45-74 were divorced, compared to $14.7 \%$ among men.

Another family-related indicator that could have an effect on mortality differences between men and women is the fertility level: a higher level of fertility would suggest that, on average, gender roles and values were more traditional, which could inhibit women from adopting certain risky behaviours. Even in the 1960s there were still marked differences in fertility levels. This was particularly the case between the most urbanised regions of the Randstad (the period total fertility rate/TFR in the Amsterdam area was just 2.2) and the "BibleBelt" (with a maximum value of 3.9 in Zuidwest-Friesland). The TFRs for 1985 were used for the second study period. Both absolute fertility and regional differences had declined, but the regional pattern was similar. Fertility rates were between 1.3 children per childbearing women in Groot-Amsterdam and 1.9 in Noord-Overijssel.

\section{Material and methods}

The data used refers to 40 so-called 'COROP' regions in the Netherlands. These are statistical regions between the administrative levels of the province and the municipality. The median population size was about 270 thousand inhabitants in 1980 and 317 thousand in 1999. ${ }^{3}$ This subdivision, which was introduced in the

3 Due to the low population size of the Delfzijl region, this region was combined with the adjacent region Oost-Groningen. The reclaimed area of Flevoland was excluded because the majority of the population are first generation (healthy) internal and external migrants and are therefore likely to bias the results, thus leaving 38 regions for the analyses, as shown in Figure 1. 
early 1970s, is based on the relationship between one central (urban) place and the surrounding area that is focused on this central place (or node) (Vliegen 1999).

The numbers of deaths by age, sex, year of death, region of residence and cause of death were extracted from a large data file supplied by Statistics Netherlands (CBS). Causes of death were selected based on the level of sex differences in mortality (a male/female mortality ratio of 1.5 or more) and a minimum number of deaths (at least $1 \%$ of all deaths). This resulted in the selection of five of the most important cause-of-death groups plus eight specific diseases for the initial analysis. During the time period covered, deaths were classified according to two different International Classifications of Diseases (ICD-9 for the period 1980-83 and ICD-10 for the period 1996-99). The change in cause-of-death classification in 1996 did not have any significant effect on the mortality trend of the causes of death relevant for this research (see Figure Annex 1). The selected causes of death and corresponding ICD codes are given in Table 1.

Table 1:

Causes of death selected for the study: ICD codes, as a percentage of total mortality, and the male to female mortality ratio, 1980-99

\begin{tabular}{lllccc}
\hline ICD-9 code ICD-10 code Name & \multicolumn{2}{c}{$\begin{array}{c}\text { \%o } \\
\text { total }\end{array}$} & $\begin{array}{l}\text { M/F } \\
\text { ratio }\end{array}$ \\
\hline $\mathbf{0 0 0 - E 9 9 9}$ & $\mathbf{A 0 0 - Y 8 9}$ & All causes & $\mathbf{1 0 0 . 0 0}$ & $\mathbf{1 . 7 2}$ \\
$140-239$ & C00-D48 & Neoplasms & $\mathbf{2 7 . 8 7}$ & $\mathbf{1 . 8 8}$ \\
$161-162$ & C32-C34 & Lung cancer & 6.73 & 7.36 \\
174 & C50 & Breast cancer & $5.32^{*}$ & - \\
$179-184$ & C51-C58 & Cancer of the female genital organs & $2.85^{*}$ & - \\
185 & C61 & Prostate cancer & $3.12^{*}$ & - \\
$\mathbf{3 9 0 - 4 5 9}$ & I00-I99 & Diseases of the circulatory system & $\mathbf{4 0 . 6 2}$ & $\mathbf{1 . 7 1}$ \\
$410-414$ & I20-I25 & Ischaemic heart disease & 17.69 & 2.24 \\
$415-429$ & I26-I52 & Other heart disease & 9.92 & $1.43 \#$ \\
$430-438$ & I60-I69 & Cerebrovascular disease & 9.58 & $1.21 \#$ \\
$\mathbf{4 6 0 - 5 1 9}$ & J00-J99 & Diseases of the respiratory system & $\mathbf{8 . 1 5}$ & $\mathbf{2 . 5 3}$ \\
$480-486$ & J12-J18 & Pneumonia & 3.10 & 1.52 \\
$490-496$ & J40-J47 & Chronic lower respiratory diseases & 4.29 & 3.94 \\
$\mathbf{5 2 0 - 5 7 9}$ & K00-K93 & Diseases of the digestive system & $\mathbf{3 . 6 2}$ & $\mathbf{1 . 3 1}$ \\
$\mathbf{7 8 0 - 7 9 9}$ & R00-R99 & Symptoms, signs and ill-defined conditions & $\mathbf{4 . 0 3}$ & $\mathbf{1 . 6 4}$ \\
E800-E999 & V01-Y89 & External causes of injury and poisoning & $\mathbf{4 . 3 0}$ & $\mathbf{1 . 8 6}$ \\
E800-E848 & V01-V99 & Transport accidents & 1.16 & 2.83 \\
E950-E959 & X60-X84 & Suicide and self-inflicted injury & 1.22 & 1.92 \\
& & Remainder of main causes & & $\mathbf{1 1 . 4 1}$ & $\mathbf{1 . 8 1}$ \\
\hline
\end{tabular}

* Pertains to gender-specific total

\# Although these two causes did not record a sex ratio of more than 1.5 , the reason for their inclusion was that they both contributed almost $10 \%$ of all deaths.

$\wedge$ Not in study 
In order to reduce random fluctuations in the regional figures, data were aggregated into two four-year periods: 1980-83, and 1996-99. The data distinguished seven age groups: <1, 1-24, 25-44, 45-64, 65-74, 75-84 and 85+. Details of the total population at risk by sex and age were obtained from unpublished CBS data. For each of the two cross-sections as well as between the two periods male-female mortality differences were analysed using the method of Pollard (1989) that decomposes differences in life expectancy at birth in terms of years of life into specific age- and cause-of-death-specific contributions.

The exogenous variables chosen for the multivariate analysis were obtained from various sources and publications mainly by CBS (see Table Annex 1). They may be distinguished into four types, the first three of which are indicative of the changes that have occurred in the position of men and women and may therefore shed some light on the observed changes in gender differences in mortality. These are a) socioeconomic factors that relate to the changing employment and educational status of men and women (unfortunately, no reliable data could be obtained on sex-specific income levels for regions); b) factors that are associated with familial gender roles (fertility levels and divorce); and c) behavioural factors (smoking, alcohol consumption and three driving-related indicators). As no agespecific smoking data could be obtained, we used gender differences in lung cancer mortality for several of the analyses. Lung cancer is considered to be a good alternative as it is almost exclusively caused by smoking and therefore a good indicator of smoking intensity (Barendregt et al. 2002). Finally, we used information on some contextual factors that might confound the regional gender differences in mortality: wage and income inequality (see e.g., Kennedy et al. 1996), indicators of relative deprivation (see e.g., Phillimore et al. 1994), urbanisation level (see e.g., Mackenbach and Kunst 1995), religious beliefs (see e.g., Jarvis and Northcott 1987) and ethnic composition (see e.g., Van Wersch et al. 1997). ${ }^{4}$

4 The variables overcrowded housing, urbanisation and the proportion of ethnic minorities were excluded from the multivariate analysis due to a high $(>0.8)$ zero-order correlation with one or more of the other variables. Urbanisation remained in the analysis for traffic accidents on the theoretical ground that higher urbanisation would be associated with better roads, more public transport and therefore fewer fatal traffic accidents with lower sex differences. As the variable divorce was highly associated with urbanisation it was excluded from this analysis. The proxy for income inequality was excluded from all analyses due to measurement bias, because the highest levels were often found in the wealthiest regions with low levels of deprivation and favourable mortality. Indeed, the literature suggests that the Gini coefficient may be more useful when testing the effects on health of extreme deprivation (Kennedy et al. 1998). Instead, an index of deprivation was constructed similar to that of Phillimore et al. (1994) by aggregating the standardised $\mathrm{z}$-scores of three non-gender-specific variables that reflect distinctive aspects of material well-being, namely unemployment, housing tenure and the availability of central heating. Lack of data on total alcohol consumption prevented its effect on lung cancer to be tested. Finally, it was decided to eliminate the variable gender differences in unemployment from all analyses after none of the multivariate results showed any significant effect on gender differences in mortality. One reason could be because of low gender 
As for many of these indicators no time series data could be obtained or reconstructed, the analysis is restricted to a comparison between the periods 198083 and 1996-99 and an analysis of the change over time ${ }^{5}$. Given the time lag that exists between exposure and outcome, earlier data were obtained for a number of socioeconomic and gender-role variables ${ }^{6}$. In some instances the information on the independent variable applied to the same cohort for which information on the dependent variable was available at a later moment in time ${ }^{7}$. Summary statistics of the final variables are listed in Table 2.

Ordinary least squares (OLS) regression was used to examine the statistical associations between the indicators of the changing social and economic position of men and women and gender differences in mortality for each region and period. Gender differences in mortality were measured by the age- and causespecific contributions to the gender differences in life expectancy. Although none of the remaining variables showed a zero-order correlation of more than 0.8 with any other individual variable (see Table 3), regressor variables may still show severe multicollinearity, a condition that complicates estimating the separate effects of each variable via regression analysis. As this did not appear to be the case after analysing the Variance Inflation Factors ${ }^{8}$ no other variables were removed from the analysis, while for the multivariate regression analysis the stepwise technique ${ }^{9}$ could be employed in order to obtain reduced models that

differences in unemployment, meaning that only a very strong effect of unemployment on mortality at the individual level could provoke an effect at the regional level.

5 With regard to the latter, we controlled for the average gender difference in mortality between the two periods. This was to adjust for the possible bias of regression towards the mean, as regions with high levels of gender inequality in mortality in 1980-83 are statistically more likely to experience larger declines in gender differences in mortality than regions with already low levels of gender inequality.

6 No time lags were considered for traffic accident mortality. This led to the exclusion of the variable secondary sector employment from this analysis because no data could be obtained for the second cross-section, while the lack of sex-specific COROP data on total consumption patterns meant that the effect of alcohol on sex differences in traffic accidents could not be tested.

7 For example, the effect of labour force participation and unemployment among 35-64 year olds in, respectively 1973 and 1987, was tested on mortality among 45-74 year olds in 1980-83 and 1996-99.

8 Variance Inflation Factor scores (VIFs) will be quite large if the regressor variable has a strong linear association with the remaining regressors. This supplies the user with an indication of which coefficients are adversely affected and to what extent. In case a VIF score exceeds 10 one should consider variable deletion to combat the problem (see also Myers 1990). The test for multicollinearity was carried out for the sex difference analyses only, as the same variables were later used in the sex-specific analyses in order to be able to compare the results.

9 This procedure starts off with the selection of the most significant variable and adds/removes those that meet/no longer meet the criteria of significance until there is no further change in the model composition. A variable was entered into the model when the significance value was less than 0.1 or less than 0.2 if it was the only socioeconomic or gender role variable in the model or an important variable in one of the sex-specific models. 
only include statistically significant variables. ${ }^{10}$ The robustness and reliability of the model was verified by comparing the regression coefficients with the model that included all variables. ${ }^{11}$

Table 2:

Summary statistics of life expectancy and the independent variables used in multivariate analysis: Regional minimum, maximum and average values for women, men and their difference for the study periods 1980-83, 1996-99, as well as the change between the two periods ${ }^{\mathrm{a}}$

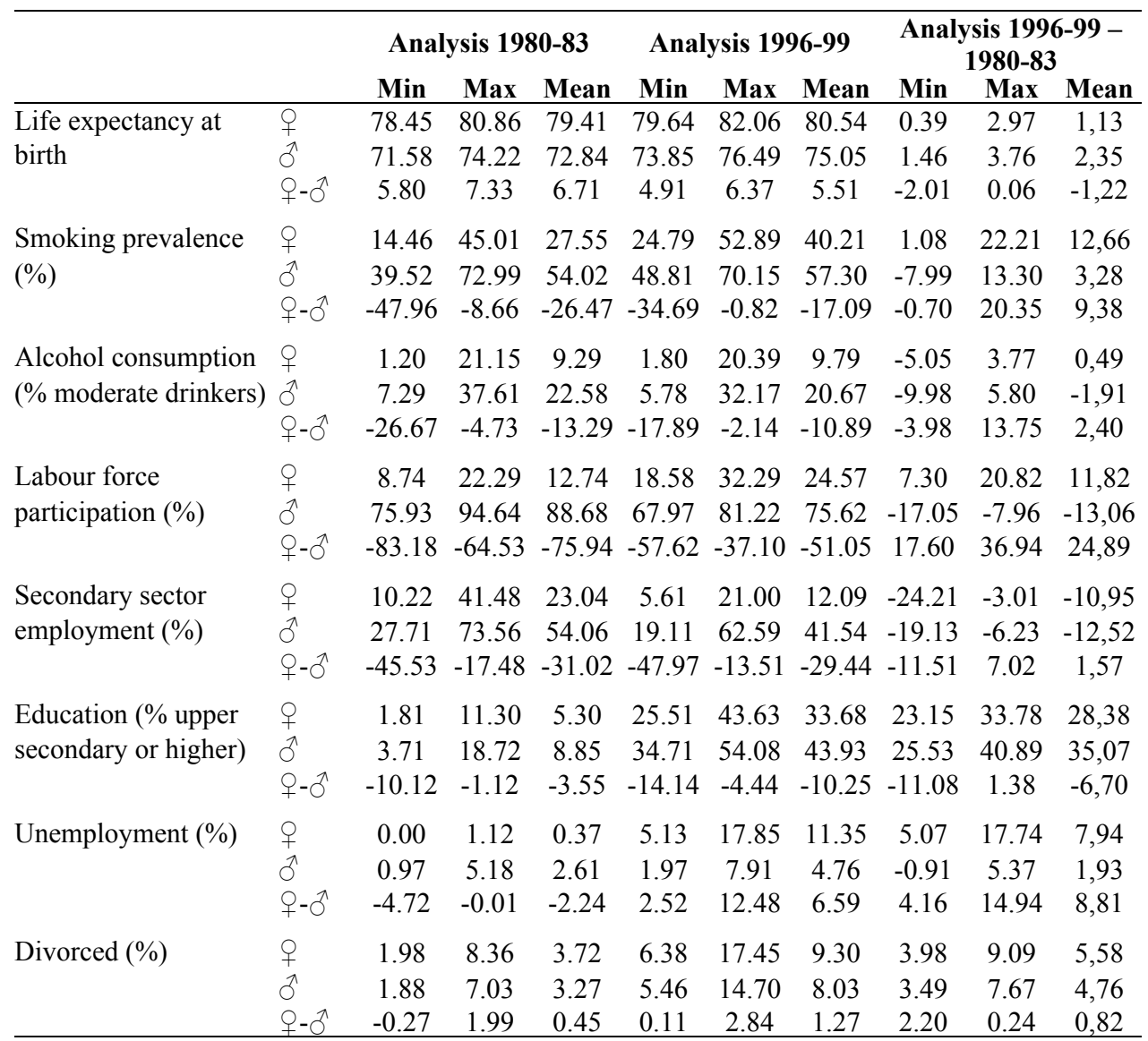

Table continued on the next page

10 It was decided not to reduce the number of variables by creating a small set of scales because of the difficulties for both the interpretation and comparability of the generated components.

11 Although the inherent presence of multicollinearity did allow several variables either to become significant or insignificant after excluding those variables that observed the least association with the dependent variable, changes in the regression coefficient were generally small and on no occasion did the direction of the association between a significant variable and a mortality indicator change. 
Table 2 (continued)

\begin{tabular}{|c|c|c|c|c|c|c|c|c|c|c|}
\hline & & \multicolumn{3}{|c|}{ Analysis 1980-83 } & \multicolumn{3}{|c|}{ Analysis 1996-99 } & \multicolumn{3}{|c|}{$\begin{array}{c}\text { Analysis 1996-99 - } \\
1980-83\end{array}$} \\
\hline & & Min & Max & Mean & Min & Max & Mean & Min & Max & Mean \\
\hline \multicolumn{2}{|l|}{ TFR } & 2.27 & 3.94 & 3.03 & 1.29 & 1.91 & 1.56 & -2.08 & -0.98 & $-1,47$ \\
\hline \multicolumn{2}{|l|}{ Wages (Dfl) } & 25800 & 29850 & 27304 & 36550 & 45400 & 40291 & 10620 & 15550 & 12994 \\
\hline \multicolumn{2}{|c|}{ Deprivation Index (Z-score) } & $-2,73$ & 5.25 & 0.00 & -2.86 & 6.55 & 0.00 & -1.85 & 3.41 & 0.00 \\
\hline \multicolumn{2}{|c|}{ Total unemployment rate (\%) } & 1,81 & 8.25 & 4.07 & 2.35 & 9.20 & 4.64 & -2.57 & 2.97 & 0.57 \\
\hline \multicolumn{2}{|l|}{$\%$ of rental housing } & 39.00 & 82.00 & 54.16 & 34.04 & 72.45 & 45.75 & -15.97 & 0.24 & $-8,41$ \\
\hline \multicolumn{2}{|c|}{$\%$ without central heating } & 12,00 & 53.00 & 33.03 & 3.25 & 28.58 & 12.33 & -35.32 & -5.12 & -20.69 \\
\hline \multicolumn{2}{|c|}{$\begin{array}{l}\text { Religious affiliation (\% votes } \\
\text { small Christian parties) }\end{array}$} & 18,50 & 51.60 & 34.18 & 10.68 & 41.63 & 24.24 & -22.56 & -1.42 & -9.94 \\
\hline \multicolumn{2}{|c|}{ Urbanisation (pop $/ \mathrm{km}^{2}$ ) } & 135 & 3046 & 621 & 146 & 3145 & 664 & -93 & 185 & 43 \\
\hline \multicolumn{2}{|c|}{ Motor vehicles per pop of 100} & 32,66 & 39.62 & 35.97 & 34.68 & 46.33 & 39.25 & -1.03 & 7.78 & 3.28 \\
\hline Driving licence & $\begin{array}{l}q \\
\hat{0} \\
0-\hat{0}\end{array}$ & & & & $\begin{array}{r}60.00 \\
77.20 \\
-23.81\end{array}$ & $\begin{array}{r}80.30 \\
91.90 \\
-11.58\end{array}$ & $\begin{array}{c}70.68 \\
87.67 \\
-16.99\end{array}$ & & & \\
\hline $\begin{array}{l}\text { Distance travelled } \\
(\mathrm{km} / \text { day })\end{array}$ & $\begin{array}{l}q \\
\hat{0} \\
0-\hat{0}\end{array}$ & & & & $\begin{array}{c}20.42 \\
30.04 \\
-15.94\end{array}$ & $\begin{array}{l}30.44 \\
44.64 \\
-8.63\end{array}$ & $\begin{array}{c}26.43 \\
38.48 \\
-12.06\end{array}$ & & & \\
\hline
\end{tabular}

Note:

Values exclude the region of Flevoland. See Table Annex 1 for the definitions, sources and time frame of the exogenous data. Mean values are arithmetic averages. 
Table 3:

Correlation matrix of the independent variables used in the multivariate analyses of gender differences in total mortality, lung cancer and IHD

\begin{tabular}{|c|c|c|c|c|c|c|c|c|c|c|}
\hline \multirow{2}{*}{$1980-83$} & \multirow[t]{2}{*}{ PART } & UNEM & \multirow[t]{2}{*}{ SEC } & \multirow{2}{*}{ EDU } & TFR & \multicolumn{3}{|c|}{ DIVOR SMOK ALC } & \multirow{2}{*}{\multicolumn{2}{|c|}{ WAGE DEPRI }} \\
\hline & & & & & & & & & & \\
\hline \multicolumn{11}{|l|}{ PART } \\
\hline UNEMP & -0.09 & & & & & & & & & \\
\hline SEC & 0.34 & -0.10 & & & & & & & & \\
\hline EDU & -0.20 & -0.19 & -0.43 & & & & & & & \\
\hline TFR & -0.65 & -0.15 & -0.39 & 0.55 & & & & & & \\
\hline DIVOR & 0.30 & 0.33 & 0.41 & -0.42 & -0.52 & & & & & \\
\hline SMOK & -0.07 & 0.06 & 0.08 & -0.36 & -0.05 & -0.23 & & & & \\
\hline ALC & 0.02 & -0.16 & 0.13 & 0.09 & 0.24 & 0.03 & -0.29 & & & \\
\hline WAGES & -0.21 & 0.41 & 0.08 & -0.42 & -0.38 & 0.53 & 0.06 & -0.24 & & \\
\hline DEPRIV & 0.45 & -0.35 & 0.21 & 0.05 & -0.19 & 0.18 & -0.37 & 0.26 & -0.48 & \\
\hline RELIG & -0.20 & -0.05 & -0.17 & 0.06 & 0.45 & -0.46 & 0.50 & 0.07 & -0.07 & -0.50 \\
\hline \multicolumn{11}{|l|}{ 1996-99 } \\
\hline \multicolumn{11}{|l|}{ PART } \\
\hline UNEMP & -0.37 & & & & & & & & & \\
\hline SEC & 0.49 & -0.08 & & & & & & & & \\
\hline EDU & 0.08 & 0.01 & 0.18 & & & & & & & \\
\hline TFR & -0.71 & 0.11 & -0.19 & 0.06 & & & & & & \\
\hline DIVOR & 0.56 & -0.10 & 0.70 & -0.03 & -0.42 & & & & & \\
\hline SMOK & -0.48 & 0.18 & -0.41 & 0.11 & 0.30 & -0.72 & & & & \\
\hline ALC & 0.00 & -0.25 & -0.02 & 0.44 & 0.24 & -0.16 & 0.16 & & & \\
\hline WAGES & 0.03 & -0.12 & 0.24 & -0.50 & -0.14 & 0.53 & -0.33 & -0.13 & & \\
\hline DEPRIV & 0.44 & -0.15 & 0.16 & 0.39 & -0.20 & 0.12 & -0.27 & 0.14 & -0.59 & \\
\hline RELIG & -0.56 & -0.07 & -0.29 & 0.13 & 0.77 & -0.59 & 0.42 & 0.26 & -0.23 & -0.27 \\
\hline \multicolumn{11}{|c|}{$96 / 99-80 / 83$} \\
\hline \multicolumn{11}{|l|}{ PART } \\
\hline UNEMP & -0.39 & & & & & & & & & \\
\hline SEC & 0.19 & -0.22 & & & & & & & & \\
\hline EDU & 0.47 & -0.25 & 0.25 & & & & & & & \\
\hline TFR & 0.02 & -0.16 & 0.03 & -0.20 & & & & & & \\
\hline DIVOR & 0.45 & -0.12 & 0.32 & 0.06 & 0.38 & & & & & \\
\hline SMOK & -0.30 & 0.42 & -0.31 & 0.03 & -0.44 & -0.43 & & & & \\
\hline ALC & 0.09 & -0.30 & 0.02 & -0.02 & 0.05 & -0.06 & -0.08 & & & \\
\hline WAGES & 0.24 & -0.26 & 0.24 & -0.14 & 0.44 & 0.49 & -0.41 & 0.39 & & \\
\hline DEPRIV & -0.11 & -0.21 & 0.15 & -0.18 & -0.05 & 0.14 & -0.12 & -0.02 & -0.02 & \\
\hline RELIG & 0.09 & 0.21 & 0.26 & 0.14 & -0.09 & -0.12 & 0.40 & -0.08 & -0.31 & -0.14 \\
\hline
\end{tabular}




\section{Results}

\subsection{Regional changes in the female/male mortality gap and changes in the mortality sex ratio}

Although life expectation increased for both sexes, the male-female mortality gap declined in the Netherlands between 1980-83, the peak period of excess male mortality, and 1996-99. Gender differences between regions varied between 5.8 and 7.3 years in 1980-83 and 4.9 and 6.4 years in 1996-99. With a few exceptions, regions in the south of the country displayed the smallest differences in the earlier period and regions in the northwest and west in the latter period. There was no unequivocal geographical pattern of large gender differences in life expectancy.

Between the early 1980s and the late 1990s, male and female life expectancy increased in all studied regions. With the exception of one region (ZeeuwsVlaanderen), the increase in life expectancy between the two periods was larger everywhere for men than for women. For the entire country, men closed the gap on women in the life expectancy at birth by 1.2 years. In central and western parts of the country the decline in the gender gap ranged between 1.4 and 2.0 years, while in all southern regions it was less than average.

Age groups 45-64 and 65-74 were mainly responsible for gender difference in life expectancy in the first period, each age group contributing just over two years (61\% of the total difference; see Table 4). In the period 1996-99, this age pattern had shifted, as the highest contributions were found among age groups 65-74 and 75-84. The contributions were 1.7 and 1.5 years, respectively, equalling $57 \%$ of the total difference in life expectancy at birth between men and women.

In terms of causes of death, diseases of the circulatory system contributed most to excess male mortality in the period 1980-83 (2.9 years), particularly ischaemic heart disease (IHD) (2.1 years). ${ }^{12}$ Cancer followed with 1.8 years, lung cancer being the largest contributor within this cause-of-death category (1.5 years), although the two groups of cancers that only affect women, i.e., breast cancer ${ }^{13}$ and cancer of the female genital organs, reduced excess male mortality by no less than 0.9 years. Prostate cancer was responsible for 0.3 years of the excess male mortality. The third major group was external causes of death. Just over half of the 0.6 years that this group contributed to the higher life expectancy of women was from traffic accidents. Diseases of the respiratory system were responsible for a similar part of the total life expectancy difference as external causes.

The absolute contributions of the most important causes of death to the gender difference in life expectancy in 1996-99 were lower than in the first period. The

12 Cause-of-death results relate to the total for all ages.

13 The average number of male deaths for breast cancer is very small (about 30 per year). 
rank order of the causes of death remained similar. Circulatory system diseases contributed 2.1 years, cancer 1.5 years, followed by diseases of the respiratory system ( 0.7 years) and external causes ( 0.5 years).

There were also spatial variations in the contribution that each cause of death made to the difference in gender mortality. As for IHD, the northern regions showed the largest gender differences in both periods while the west and southwest of the country showed the least. A similar pattern was found for traffic accidents. Gender mortality differences from both lung cancer and respiratory system diseases were highest in the southwest and lowest in the north (1980-83) and west (1996-99) of the country.

The difference between male and female mortality between the two periods declined in all but the last two age categories. The largest part of the decline in excess male mortality occurred between ages 45 to 74 (about 1.2 years). Concurrently, the gender-gap increased about a quarter of a year for those above age 75. In age group 0-44 mortality differences declined by a quarter of a year. In terms of causes of death, the largest contributors were IHD ( 0.9 years) and lung cancer ( 0.5 years), while traffic accidents made a small contribution ( 0.1 years). The aggregate of these three specific causes of death was actually greater than the total reduction of 1.2 years, as developments in the incidence of cancer of the female genital organs, other heart diseases, prostate cancer, chronic lower respiratory diseases and suicide actually all slightly enhanced the female advantage, though each less than 0.1 years.

As developments in IHD, lung cancer and traffic accident mortality caused a decline in mortality differences between females and males, we limited our further analyses to these three causes of death. The aetiology of these diseases already indicates that behavioural factors play an important role in this changing pattern.

Table 4:

Age- and cause of death contributions to gender differences in life expectancy at birth, 1980-83, 1996-99 and difference between the two periods, the Netherlands, in years

\begin{tabular}{|c|c|c|c|c|c|c|c|c|}
\hline \multirow[b]{2}{*}{ Cause of death } & \multicolumn{8}{|c|}{ Age group } \\
\hline & $\begin{array}{l}\text { Total } \\
\text { ages }\end{array}$ & $\mathbf{0}$ & $1-24$ & $\begin{array}{c}25- \\
44\end{array}$ & $\begin{array}{l}45- \\
64\end{array}$ & $\begin{array}{l}65- \\
74\end{array}$ & $\begin{array}{l}75- \\
84\end{array}$ & $85+$ \\
\hline 1980-83 & & & & & & & & \\
\hline All causes & 6.71 & 0.16 & 0.33 & 0.40 & 2.04 & 2.08 & 1.37 & 0.33 \\
\hline Neoplasms & 1.81 & & & -0.05 & 0.44 & 0.77 & 0.51 & 0.11 \\
\hline Malignant neoplasm of trachea, bronchus \& lung & 1.48 & & & & 0.54 & 0.57 & 0.30 & 0.05 \\
\hline Malignant neoplasm of breast & -0.58 & & & -0.09 & -0.30 & -0.11 & -0.06 & \\
\hline Malignant neoplasm of female genital organs & -0.31 & & & & -0.15 & -0.08 & & \\
\hline Malignant neoplasm of prostate & 0.31 & & & & & 0.10 & 0.12 & 0.05 \\
\hline Diseases of the circulatory system & 2.90 & & & 0.14 & 1.18 & 0.93 & 0.53 & 0.11 \\
\hline Ischaemic heart disease & 2.11 & & & 0.12 & 0.95 & 0.64 & 0.33 & 0.07 \\
\hline Other heart disease & 0.38 & & & & 0.13 & 0.11 & 0.09 & \\
\hline Cerebrovascular disease & 0.23 & & & & 0.06 & 0.10 & 0.07 & \\
\hline
\end{tabular}




\begin{tabular}{|c|c|c|c|c|c|c|c|c|}
\hline \multirow[b]{2}{*}{ Cause of death } & \multicolumn{8}{|c|}{ Age group } \\
\hline & $\begin{array}{l}\text { Total } \\
\text { ages }\end{array}$ & $\mathbf{0}$ & $1-24$ & $\begin{array}{c}25- \\
44\end{array}$ & $\begin{array}{l}45- \\
64 \\
\end{array}$ & $\begin{array}{l}65- \\
74\end{array}$ & $\begin{array}{l}75- \\
84\end{array}$ & $85+$ \\
\hline Diseases of the respiratory svstem & 0.59 & & & & 0.08 & 0.20 & 0.21 & 0.08 \\
\hline Pneumonia & 0.08 & & & & & & & \\
\hline Chronic lower respiratory diseases & 0.44 & & & & 0.07 & 0.16 & 0.16 & 0.05 \\
\hline Diseases of the digestive system & 0.15 & & & & 0.06 & 0.05 & & \\
\hline Symptoms, signs and ill-defined conditions. & 0.34 & & & 0.06 & 0.12 & 0.06 & & \\
\hline External causes of injury and poisoning & 0.63 & & 0.25 & 0.21 & 0.11 & & & \\
\hline Transport accidents & 0.33 & & 0.16 & 0.09 & & & & \\
\hline Suicide and self-inflicted injury & 0.12 & & & 0.05 & & & & \\
\hline Remainder of main causes & 0.29 & 0.12 & & & & & & \\
\hline 1996-99 & & & & & & & & \\
\hline All causes & 5.51 & 0.09 & 0.25 & 0.31 & 1.23 & 1.67 & 1.49 & 0.47 \\
\hline Neoplasms & 1.49 & & & -0.07 & 0.21 & 0.63 & 0.53 & 0.17 \\
\hline Malignant neoplasm of trachea, bronchus \& lung & 0.97 & & & & 0.26 & 0.38 & 0.27 & 0.06 \\
\hline Malignant neoplasm of breast & -0.60 & & & -0.08 & -0.31 & -0.12 & -0.07 & \\
\hline Malignant neoplasm of female genital organs & -0.26 & & & & -0.11 & -0.07 & & \\
\hline Malignant neoplasm of prostate & 0.38 & & & & & 0.11 & 0.15 & 0.08 \\
\hline Diseases of the circulatory system & 2.09 & & & 0.07 & 0.64 & 0.69 & 0.54 & 0.14 \\
\hline Ischaemic heart disease & 1.21 & & & 0.05 & 0.41 & 0.39 & 0.28 & 0.08 \\
\hline Other heart disease & 0.45 & & & & 0.14 & 0.13 & 0.11 & \\
\hline Cerebrovascular disease & 0.18 & & & & & 0.08 & 0.06 & \\
\hline Diseases of the respiratory system & 0.65 & & & & & 0.18 & 0.29 & 0.14 \\
\hline Pneumonia & 0.15 & & & & & & 0.07 & \\
\hline Chronic lower respiratory diseases & 0.45 & & & & & 0.13 & 0.21 & 0.09 \\
\hline Diseases of the digestive system & 0.13 & & & & 0.05 & & & \\
\hline Symptoms, signs and ill-defined conditions. & 0.29 & & & & 0.11 & 0.06 & & \\
\hline External causes of injury and poisoning & 0.52 & & 0.17 & 0.21 & 0.09 & & & \\
\hline Transport accidents & 0.21 & & 0.09 & 0.07 & & & & \\
\hline Suicide and self-inflicted injury & 0.18 & & & 0.08 & & & & \\
\hline Remainder of main causes & 0.30 & 0.07 & & & 0.09 & 0.06 & & \\
\hline $1996-98-1980-83$ & & & & & & & & \\
\hline All co & 1.20 & 0.07 & 0.08 & 0.09 & 0.81 & 0.41 & -0.12 & -0.14 \\
\hline Neoplasms & 0.32 & & & & 0.23 & 0.14 & & -0.06 \\
\hline Malignant neoplasm of trachea, bronchus \& lung & 0.51 & & & & 0.28 & 0.19 & & \\
\hline Malignant neoplasm of breast & & & & & & & & \\
\hline Malignant neoplasm of female genital organs & -0.05 & & & & & & & \\
\hline Malignant neoplasm of prostate & -0.07 & & & & & & & \\
\hline Diseases of the circulatory system & 0.81 & & & 0.07 & 0.54 & 0.24 & & \\
\hline Ischaemic heart disease & 0.90 & & & 0.07 & 0.54 & 0.25 & 0.05 & \\
\hline Other heart disease & -0.07 & & & & & & & \\
\hline Cerebrovascular disease & 0.05 & & & & & & & \\
\hline Diseases of the respiratory system & -0.06 & & & & & & -0.08 & -0.06 \\
\hline Pneumonia & -0.07 & & & & & & & \\
\hline Chronic lower respiratory diseases & & & & & 0.05 & & -0.05 & \\
\hline Diseases of the digestive system & & & & & & & & \\
\hline Symptoms, signs and ill-defined conditions & 0.05 & & & & & & & \\
\hline External causes of injury and poisoning & 0.11 & & 0.08 & & & & & \\
\hline Transport accidents & 0.12 & & 0.07 & & & & & \\
\hline Suicide and self-inflicted injury & -0.06 & & & & & & & \\
\hline Remainder of main causes & & 0.05 & & & -0.05 & & & \\
\hline
\end{tabular}

\section{Note:}

Only the main cause of death categories and those causes used in the multivariate analyses (in italics) are shown. Age-specific contributions less than \pm 0.05 are not given. Sum of parts may not add up to total due to rounding. 
When the decline in the female advantage in life expectancy between the two periods is decomposed into contributions from lung cancer, IHD and traffic accidents, the spatial pattern that arises diverges from the pattern observed for total mortality. A decline in excess male mortality due to lower incidence of lung cancer was particularly evident in the western regions. Here contributions were all -0.5 years or lower, while male lung cancer mortality compared to that of females only marginally improved in the north of the country (Figure 2a). With respect to IHD, the pattern was somewhat different as most northern regions recorded the highest declines (Figure 2b). Even so, the regions with the lowest declines still showed at least a half-year reduction of the female mortality advantage, thus indicating the importance of this cause of death in the general decline in gender differences in mortality. For traffic accidents, the results were less clear-cut. Figure $2 \mathrm{c}$ indicates that both the north and the west had regions that recorded close to no decline in gender differences in mortality as well as declines greater than -0.1 years in adjacent regions.

\subsection{Cross-sectional multivariate analysis of the periods 1980 - 83 and 1996-99}

Cross-sectional analyses were conducted for the periods 1980-83 and 1996-99. It should be noted that as it is a regression analysis of spatial units, spatial autocorrelation may cause a problem (Anselin 1988). Spatial autocorrelation of the error terms in the regression equation occurs if omitted variables that affect mortality show a spatial pattern. In that case, the error terms are not independent, but correlated, whereby the correlation depends on the distance between the regions. We tested, using the model with all selected variables, irrespective of their significance, whether the residual terms were spatially correlated for each cause of death, but this turned out not to be the case and therefore standard multiple regression techniques could be employed. ${ }^{1}$

\section{Total mortality}

The multivariate results showed that the smoking proxy lung cancer contributed strongly to excess male mortality between ages 45 and 74 for the period 1980-83 $\left(\right.$ Table $5^{2}$ ). Some support was also given to the effect of socioeconomic variables, as gender differences in both labour force participation and education were

1 This test was performed using a binary matrix of inter-regional linkages, whereby the link between neighbouring regions in the matrix is 1 , and for non-neighbouring regions it is 0 .

2 As the analysis proved quite complex, an explanation of how the table should be read including several examples, is given in the footnotes of the table. 


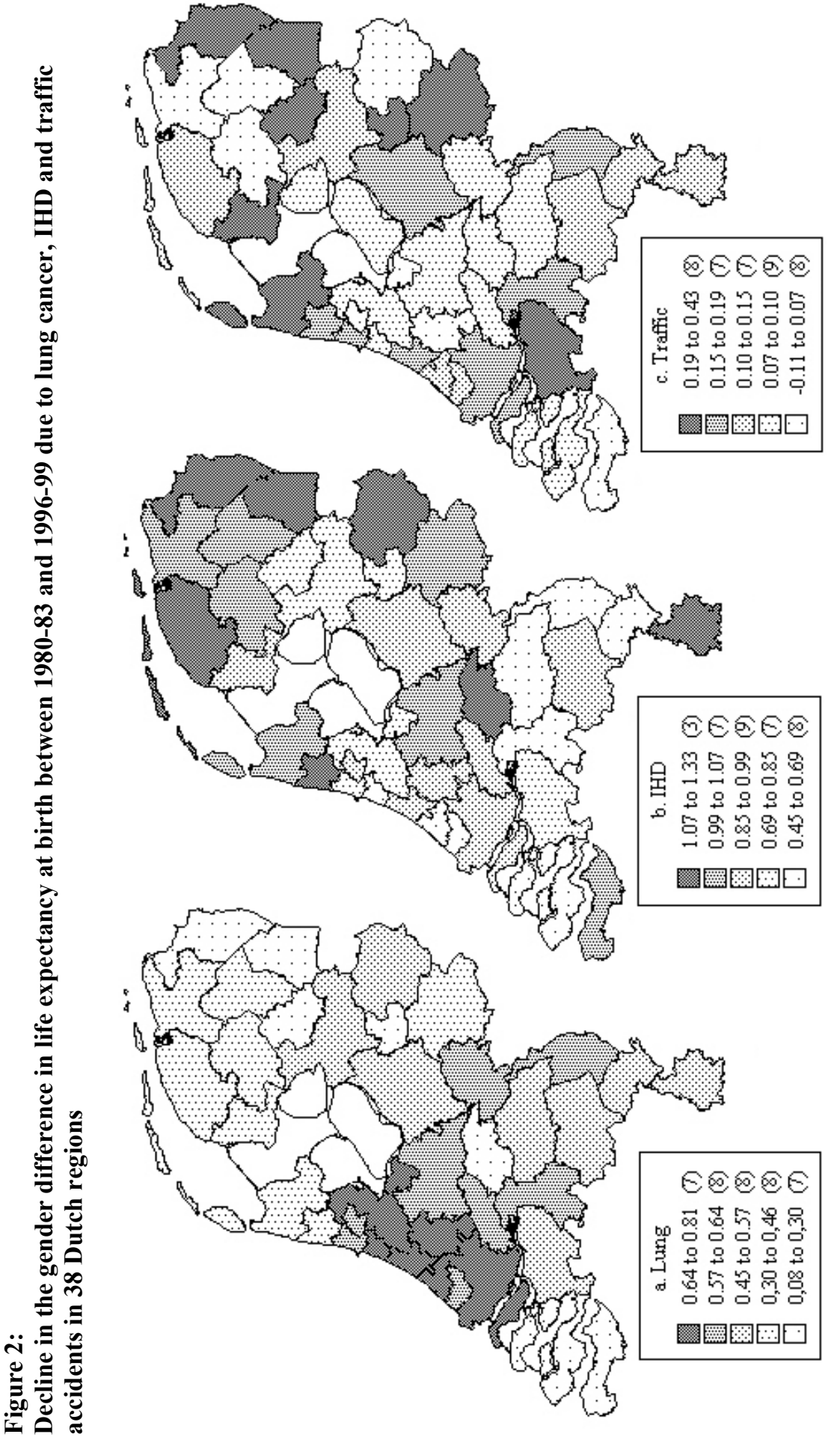




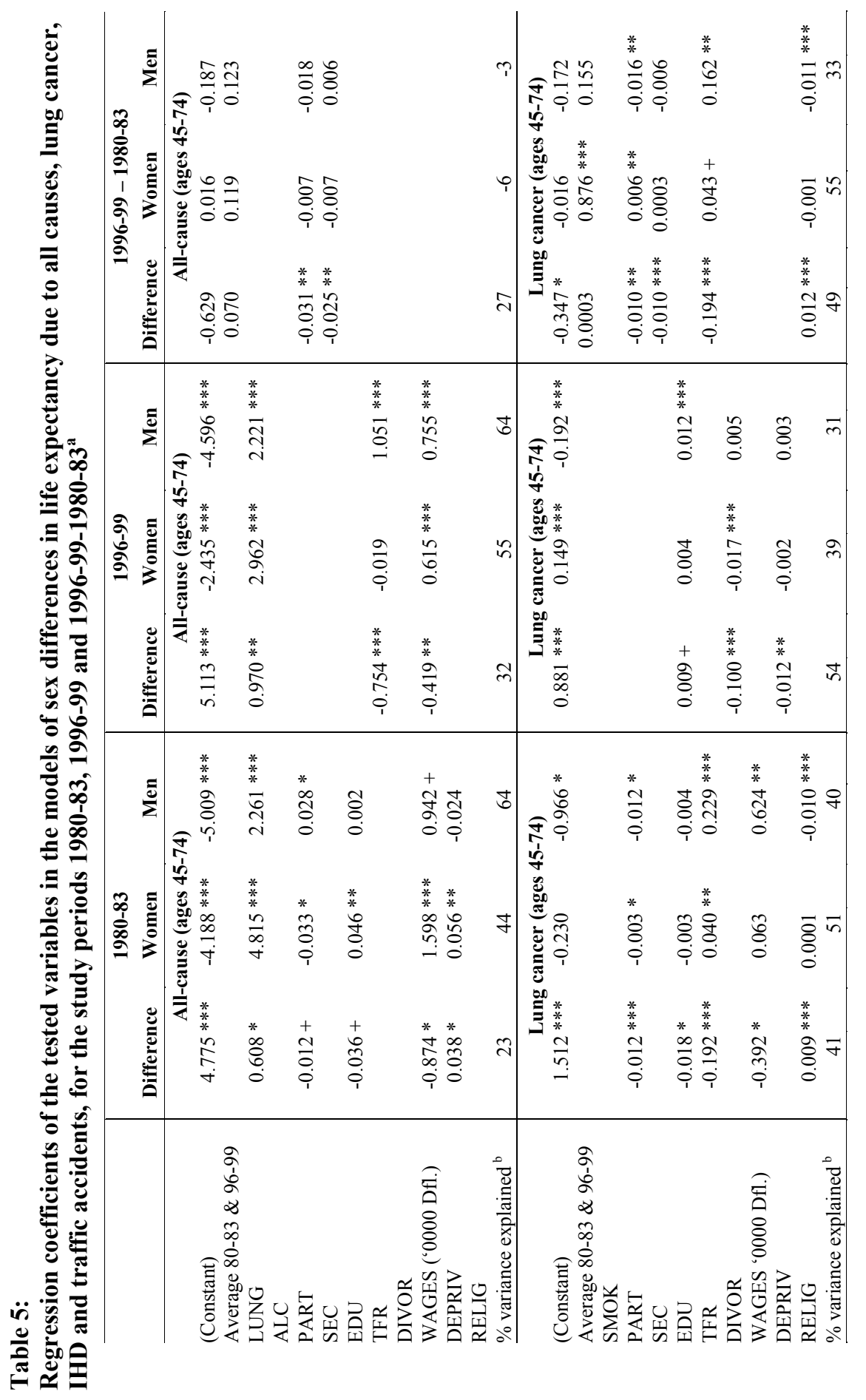




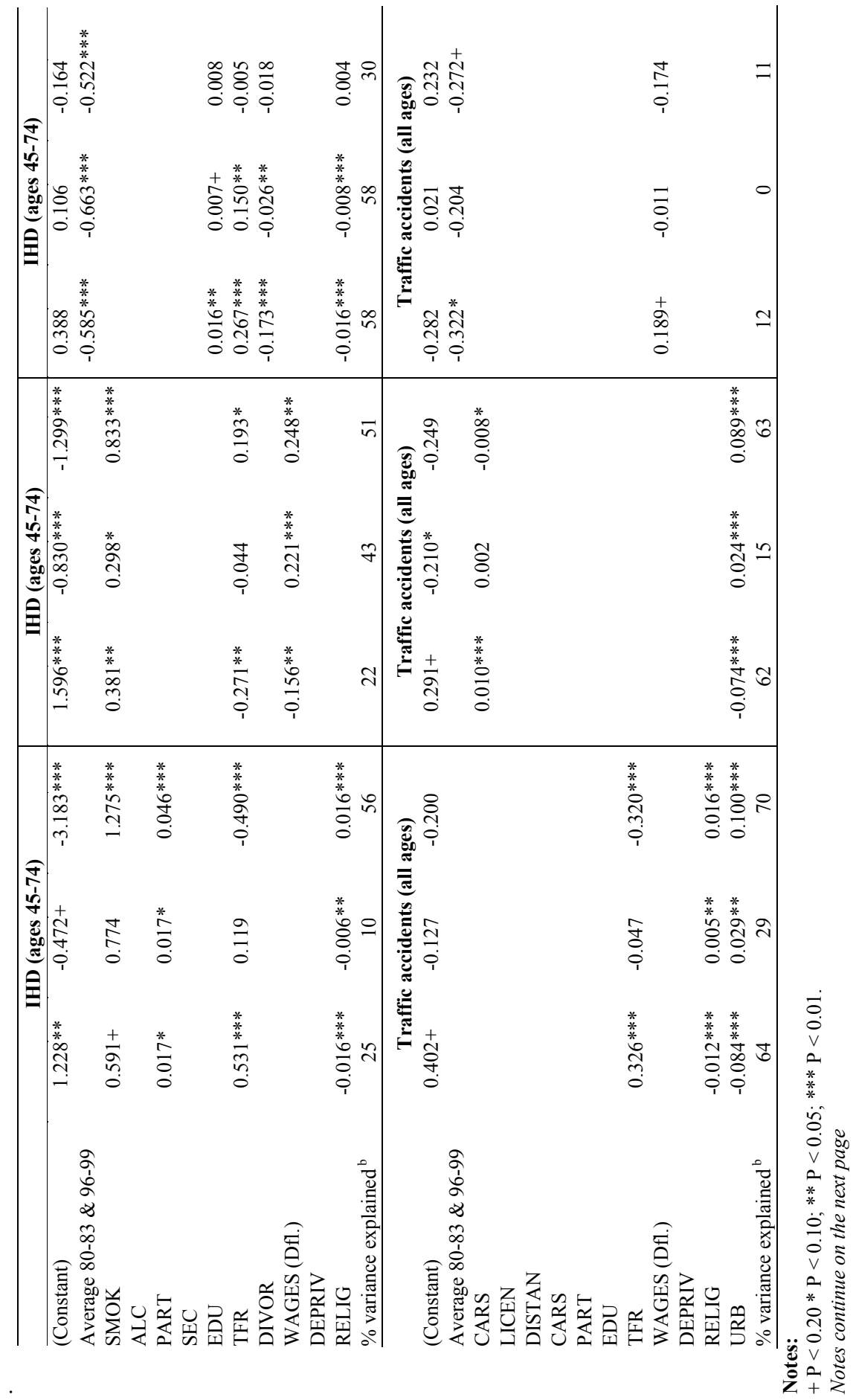


Notes Table 5 (continued):

${ }^{a}$ How to interpret the table:

In the analysis of sex differences the dependent variable is the contribution of the age- and cause-of-death category to the sex difference in years of life expectancy, with the COROP region as the unit of analysis $(\mathrm{N}=38)$. As women have lower mortality rates than men with regard to the age- and cause-of-death categories selected for these analyses, this value is always positive. Therefore, a positive regression coefficient signifies that the higher the value of the independent variable, the larger the female advantage in life expectancy, i.e., the higher the excess male mortality. The interpretation becomes slightly more complicated when the independent variable is also a gender difference variable (i.e., the value for women subtracted by the value for men). For instance, a positive coefficient indicates that the higher the value for women compared to that for men (e.g., in both models for total mortality, the gains in life expectancy from lower lung cancer (i.e., less smoking)) or the lower the female deficit (as in the case of labour force participation in the 1980-83 model for IHD) the larger the gender difference in mortality.

In the sex-specific column for each period, the dependent variable is the difference in mortality between the national average and the COROP region, also expressed in terms of years of life expectancy. This value is positive when the region has lower than average mortality in this cause-of-death category. The dependent variable is more straightforward, as it pertains to the gender-specific value. Therefore, in the case of the 1980-83 total mortality model for men, higher labour force participation is associated with lower mortality. The model coefficient is positive, because lower mortality is expressed in terms of life expectancy.

In the sex difference column for the analysis over time, the value of the dependent variable is usually negative, because females have lost part of their advantage in life expectancy over time, while gender differences in some of the independent variables are also converging, as women are catching up on men (e.g., regarding labour force participation in the model for total mortality), or the situation of women has become worse (e.g., regarding divorce in the model for IHD). In these cases, the values of the independent variables are mostly positive, as the gender difference in the earlier period is subtracted from the gender difference of the latter period. Hence, the model coefficients are for instance positive when the decline in female-male life expectancy differences was associated with an increase in the male value for the independent variable in comparison to the female value (e.g., lower gender differences in IHD as women lost ground in terms of gender differences in education).

In the sex-specific column for the analysis over time, the dependent variable related to the change over time in mortality of a region relative to the country's average, i.e., if a region improved more or weakened less than the average, the value of the dependent variable is positive. In terms of the multivariate analysis this means that a positive coefficient indicates that the relative improvement in life expectancy was associated with an increase (or a smaller decrease) in the independent variable. For instance, regions where lung cancer mortality declined more than average between 1980-83 and 1996-99, the TFR declined less than average between 1969 and 1985.

${ }^{\mathrm{b}}$ Equivalent to $\mathrm{R}^{2}$ adjusted, which is lower than the standard $\mathrm{R}^{2}$ as it takes into account those regressors that do not contribute to the explanatory power of the model. The value may be negative in poorly fitted models.

${ }^{\mathrm{c}}$ Education was included here even though it was only significant at the 0.2 level, because if data for the more appropriate age group 35-64 were to be included, it would have been significant at the 0.1 level. However, for comparative purposes this was not done, as no such data were available for the second study period. Regarding the other coefficients, there were few differences in the results if education for ages 15-64 or 35-64 were used, with the exception that wages would now also have been significant at the 0.1 level.

negatively associated with gender differences in total mortality, albeit only at the $20 \%$ significance level. In the sex-specific analyses we observe that labour force participation appeared to have protective properties for men, but a detrimental effect for women. Education only had an effect on female mortality, though a protective one. The gender role variables divorce and TFR made no contribution to the explanation of the male/female mortality gap. Of the contextual factors, wages appear to reduce gender differences in mortality (although the female coefficient is slightly higher, the male coefficient has a higher elasticity, i.e., income benefits male health more than that of females, thus reducing gender differences). Deprivation increased gender differences in total mortality as it appeared to be positively associated with female life expectancy. This suggests that it is not an accurate measure of relative deprivation for a country with little extreme deprivation (see also footnote 5). The main driving force behind the 
gender differences in total mortality in 1996-99 was smoking, TFR and wages. Although it appears that the sign of the coefficient for TFR is in the wrong direction, the sex-specific analysis indicated that higher fertility levels protected male, not female health. The result for wages was similar to the earlier period.

\section{Lung cancer}

Although the results seem to suggest that regional gender differences in smoking were not responsible for regional gender differences in lung cancer, a more likely explanation is that the smoking data are unreliable or unsuited for the analysis (e.g., no age- and cohort-specific data could be obtained). It is nonetheless possible to demonstrate the role of smoking in gender differences in lung cancer mortality in an indirect way, because each of the tested variables has a known smoking gradient.

In the analysis of 1980-83, two socioeconomic variables were associated with gender differences in lung cancer mortality. Gender differences in labour force participation were negatively associated with gender differences in lung cancer mortality, which according to the sex-specific analysis occurred because paid work increased male lung cancer more than that of women. Likewise, gender differences in middle and high-level education were negatively associated with female-male differences in lung cancer mortality, although the sex-specific analyses did not provide any further insights. One gender role factor was significant in this analysis, namely TFR. Although for both men and women a larger than average number of children in a region was associated with lower mortality about 15 years later, the effect was greatest among men, and thus gender differences in lung cancer were lowest in regions with higher levels of fertility. The contextual factors wages (protective for men and thus a lowering effect on male-female mortality differences) and religion (detrimental for men and thus an increasing effect on female-male mortality differences) were also important variables. With respect to the latter, this is consistent with similar regional studies on the association between religion and regional mortality differences in the Netherlands (e.g., Mackenbach and Kunst 1995).

In the 1996-99 analysis, divorce was associated with smaller gender differences in lung cancer mortality, as it appeared to have a detrimental effect among women. Although no effect was found for men, the result was consistent with the literature. A study showed that the relative risk of dying from lung cancer for divorced women in comparison to married women was higher than for men (Joung et al. 1996). Education, thought to lower the possible psychosocial need to smoke by increasing the knowledge on health-damaging behaviour and promoting self-esteem (Davey Smith et al. 1998), was incorporated in the gender differences model because it was clearly associated with lower male lung cancer mortality and thus lower gender differences. The sex difference analysis also showed that deprivation was negatively associated with gender difference in lung cancer mortality. 


\section{Ischaemic heart disease}

In both 1980-83 and 1996-99 gender differences in smoking (measured by the proxy lung cancer) were associated with gender differences in IHD mortality, although in the early 1980s there was no effect of regional smoking differences on the spatial pattern of female IHD. This is quite plausible, as smoking became widespread among women only later. During both periods the gender role factor TFR also appeared to play a significant role in the gender gap of IHD mortality. The apparent association, however, changed over time from positive due to a damaging effect for men (i.e., increasing gender differences), to negative, as in the latter period it appeared to protect men from certain health-damaging behaviour (thus narrowing gender differences). Of the socioeconomic factors, labour force participation protected against both male and female IHD mortality in the 1980-83 period, while in the analysis for 1996-99 none of the socioeconomic factors was significant. Regarding the contextual factors, in 198083 religion reduced the gender differences in IHD. The sex-specific analysis revealed that this was because religion appeared to protect males, but not females against IHD mortality. Also significant was the context variable wages in the 1996-99 analysis, as it appeared that in the more wealthy areas gender differences were smallest. Both sex-specific results revealed that income protected against IHD.

\section{Traffic accidents}

In the analysis of traffic accidents, mortality from all ages was included, as gender differences were particularly large below age 45 . The exogenous variables were not lagged and pertained to the entire population or working-age population. Results showed that in the 1980-83 analysis higher fertility levels were associated with higher gender differences in traffic accidents. The sex-specific results indicated that this variable had a detrimental effect on male mortality, but not on female mortality. The context variable urbanisation was also significant, and had a narrowing effect on gender differences in traffic accident mortality. There was a positive association with survival among each sex, but this effect was larger for men. In the latter period, the number of cars per capita and urbanisation were the two only significant variables that could explain the gender differences in traffic accident mortality, even though the two other traffic variables included in this analysis, gender differences in average daily distance travelled and gender differences in holding a drivers' licence should have given more explanatory power as they were gender-specific variables. Nevertheless, cars per capita may still be a good proxy for gender differences in road exposure, as in family households with one car men are more likely than women to have one at their disposal, while among those who live alone, men have a higher disposable income than women, making it easier for them to own a car. Regarding the urbanisation variable, roads are often better and safer in high-density populations, where public transport is also more extensive. As these factors reduce the number 
of motor vehicle traffic accidents, it favours men more than women because their average level of displacement is higher (cf. the gender-specific coefficients ${ }^{16}$ ).

\subsection{The decline in the gender mortality gap between $1980-83$ and 1996-99}

The results of the analysis of changing gender differences over time for total mortality showed that the narrowing of the gender gap of mortality was greatest in regions with the largest declines in gender differences in labour force participation as well as secondary sector employment. This would suggest that the converging patterns in the workforce also entail coalescing patterns in occupational hazards and job stresses. No explanation could be given for the regional pattern in gender-specific characteristics that were observed. With regard to lung cancer, results showed that two of the four socioeconomic variables explained part of the decline in the gender difference in lung cancer, with the results for labour force participation and secondary sector employment being the same as for total mortality. With regard to the only gender role factor that was significant, the TFR, smaller declines in fertility were associated with larger declines in lung cancer differences between men and women. From the sexspecific analysis it seems that TFR has a protective effect on men but none on women. The only contextual factor that was significant was the religion proxy. Results showed that the largest declines in gender differences in lung cancer occurred in those regions with the largest declines in the affinity for political parties with a religious basis. In the IHD-specific analysis, the decline in the gender mortality gap was associated with both gender role factors. In the case of the TFR, the association was opposite to that for lung cancer, i.e., larger declines in fertility were associated with larger declines in gender differences in IHD mortality. Sex-specific results revealed that regions with larger declines in fertility also observed a worsening in the level of female lung cancer mortality with respect to the country's average. There was no such effect among men. With regard to divorce, increases in excess female proportion of divorcees aged 45-74 were associated with a lowering of gender differences in IHD mortality in the same age group. This might be explained by the fact that a relative worsening in the level of female IHD mortality occurred in those regions with the highest increases of divorce, as indicated by the sex-specific analysis. The only significant context variable was religion, where the largest declines in IHD mortality differences occurred in areas with the lowest reduction in the affinity to a political party with a religious basis. The fact that this result is opposite to that of lung cancer may be because the less religious north of the country was the region where male IHD was last to decline (Mackenbach et al. 1990). The

16 While strictly speaking elasticities ought to be calculated and compared when making such gender-specific comparisons, we assume that male and female urbanisation levels are similar. 
analysis of traffic accident mortality showed no significant contribution of any of the labour force or gender role variables to the decline in male-female differences. Only the context variable wages showed a small statistical association, with regions with the highest wage increases showing the smallest reduction in excess male traffic accident mortality. It should be mentioned that the poor explanation for the decline in gender differences in traffic accident mortality is likely due to the fact that regional differences were very small.

To remove the possible effect of regression to the mean, the average gender difference in life expectancy of both periods was also included. This factor had a negative significant effect on both IHD and traffic accidents. It indicates that the larger the average gender differences in mortality for the earliest period, the larger the decline in the gender gap. While there were some minor alterations in the coefficients as a result of this additional factor, it did not change the models.

Additional insights into the decline in the gender mortality gap can be obtained when the coefficients of each period are compared. For example, we observed a significant decrease in the value of the TFR coefficients in the case of IHD mortality. During 1996-99, the regions with high fertility levels (i.e., more women fulfilling traditional gender roles) recorded the lowest difference in mortality while in the earlier period, TFR showed the opposite effect, as it changed from protecting women to protecting men. On the other hand, the association between urbanisation and traffic accident mortality changed little over time, both in terms of the sex differences analysis and the sex-specific one.

\section{Summary and discussion}

Between the periods 1980-83 and 1996-99, the gender gap in mortality declined in the Netherlands by -1.2 years. Particularly the $45-74$ age group was responsible for the compression of this difference, whereas male-female mortality differences actually increased beyond age 75 . IHD and lung cancer were the two largest causes of death responsible for the decline. Regional changes in the gender mortality gap for all causes ranged from +0.1 to -2.0 years.

The impetus for this search for an explanation of the changes in gender differences in mortality was a study by Waldron (2000), who used several causal hypotheses to predict changing sex ratios in mortality. Although it is certain that at the ecological level her proposed hypotheses may prove difficult to be operationalised and tested in an unbiased manner, we feel that they can still contribute to the interpretation of our research findings. We therefore used her hypotheses to identify behavioural, socioeconomic and gender role factors for which we could obtain data and tested them for statistical association in a multivariate regression model. The models were also applied to the genderspecific data in order to ascertain if the association between a variable and the mortality indicator was the same for men as for women. 
Even though the exogenous variables were carefully selected, it was not possible to provide an overall explanation of trends in gender differences in mortality that was in line with Waldron's hypothesis. We could show, though, how important smoking was in explaining gender mortality differences during each of the two study periods. Although we were not able to confirm this with gender-specific data on smoking prevalence, the role of smoking in gender differences in total and IHD mortality was demonstrated when using lung cancer mortality as a proxy. The lack of a direct association between smoking and lung cancer mortality was probably due to the fact that we lacked cohort and smoking intensity data and because of the relatively small time lag that we could consider (just 10 years in the 1980-83 analysis, while research indicates that a substantial decline in smoking levels would bring about a decline in lung cancer only approximately 30 years later (Ruwaard 1993)).

Waldron suggested that the increased propensity of women to smoke (and to other types of behaviour with negative health effects) has been the negative consequence of interrelated changes in socioeconomic, cultural and material conditions that have contributed to female emancipation and the modernisation of gender roles which, in turn, has shifted cultural norms and relaxed restrictions on women's behaviour (Waldron 2000). Our analysis provided support to the effect of other indicators for this gender role change, though not consistently. In both cross-sectional analyses the importance of one or both gender role variables was evident in three of the four models. With regard to the socioeconomic variables, one or two of the four tested were significant in each of the models for the 1980-83 analysis, an exception being made for traffic accidents. As this included labour force participation in the models for total mortality and lung cancer, it seems to contradict the suggestion made by Waldron that "trends in women's labour force participation have had little effect on trends in gender differences in health-related behaviour or mortality" (ibid., p. 174). Nevertheless, as socioeconomic variables were only once significant in the second period, there is the possibility of a change in pathways to almost exclusively gender role variables being associated with gender differences in mortality. In terms of changes in gender differences in mortality over time, both types of variables that were tested, i.e., socioeconomic and gender role ones, were simultaneously associated with declining gender gaps in lung cancer and IHD.

With regard to the premise by Pampel (2001) - that the disruption of traditional values and the ensuing role ambiguity which allowed women to integrate into the workforce and caused the convergence in male and female deaths in traffic accidents - a likely reason why the tested variables provided little support was that the gender differences in terms of life expectancy were very small and that it was decided to analyse all ages instead of the working age group.

A final comment about the results is that we cannot dismiss the importance of the context variables wages, deprivation and religion. This was particularly the case for the period 1980-83, where in the total mortality and traffic accident 
models a significant negative association was found for wages and the indicator for religion was significant with regard to lung cancer and IHD. The result for traffic accidents could be explained by the fact that wealthier regions are likely to contain more cars and in particular second cars tend to be driven by women. Sexspecific results for religion revealed that it had no effect on female mortality. It must be said, however, that religion appears to have lost its role in the explanation of mortality differences, as in the 1996-99 analysis it was no longer significant. In the analysis for 1996-99, deprivation was the only contextual factor that played a significant role, and only for lung cancer. Sex-specific analyses revealed that the gender difference reducing effect was due to the negative effect on female health.

By comparing associations in the female-male difference analyses with the sex-specific results, we were able to obtain some additional insights. For instance, the suggested associations of some of the studied changes in the position of the sexes were different for men and women. This was the case of the gender role indicator, TFR. Rather than the expected negative association between fertility and female mortality (the contribution of maternal mortality was considered to be insignificant), and thus a positive association with the female-male mortality gap, the results for 1996-99 revealed that TFR was associated with a lower gender gap in total mortality and IHD mortality, because there was a negative association between fertility and male mortality but no association among women. One may therefore tentatively conclude that in those regions with more traditional households it is the men who retain some of the protection offered by traditional gender roles.

Although this geographical study has provided a good opportunity to study the association of changes in the position of the sexes and mortality, it nonetheless has had some serious limitations. One problem with ecological studies is the general one of establishing associations that may not be consistent over time or space, as much of the disease-related mortality is the result of an accumulation of exposures across the life course (Davey Smith 1997). Potential effects of indicators such as unemployment, divorce and smoking on mortality thus depend on the duration and time of the exposure. The fact that gender differences in mortality in the Netherlands were largest in the early 1980s does not imply that gender differences in factors affecting mortality were also largest in this period. We have tried to accommodate this by incorporating time lags in several of the variables, in some instances even with matching cohorts, but the data were still quite limited, as we were only able to lag for a fixed period. Moreover, we also lacked data for specific variables that may have been relevant in the context of gender mortality differences, including gender-specific data on income, labour force participation in terms of hours worked and more detailed data on dietary factors, alcohol and smoking patterns. 


\section{Acknowledgements}

This research was funded by the Netherlands Organisation for Scientific Research (NWO) (project number 510-03-0901). The population and mortality data were made available by Statistics Netherlands (CBS) in Voorburg, with special thanks to Pieter Korving and Gerard Verweij. We would also like to thank Ingrid Waldron, Anton Kunst and the two anonymous reviewers for their critical comments and useful suggestions. Kunst also supplied the data on the behavioural factors. A final thanks goes out to Frans Frencken of the CBS office in Heerlen who supplied the list of municipalities for each COROP region as they were in 1973.

\section{References}

Annandale, E. and K. Hunt. 2000. "Gender inequalities in health: research at the crossroads". In: E. Annandale and K. Hunt (eds.) Gender inequalities in health. Buckingham, UK, Open University Press, pp. 1-35.

Anselin, L. 1988. Spatial econometrics: methods and models. Dordrecht, The Netherlands, Kluwer Academic Publishers.

Anson, J. 2003. Sex differences in mortality at the local level: An analysis of Belgian municipalities. European Journal of Population 19: 1-28.

Barendregt, J. J., C. W. N. Looman, and H. Brom-Hansen. 2002. Comparison of cohort smoking in Denmark and The Netherlands. Bulletin of the WHO. 80(1): 26-32.

Council of Europe. 2003. Recent demographic developments in Europe 2003. Strasbourg, France, Council of Europe Publishing.

Davey Smith, G. 1997. "Socioeconomic differentials". In: D. Kuh and Y. Ben-Shlomo (eds.) A life course approach to chronic disease epidemiology. Oxford, Oxford University Press.

Davey Smith, G., C. Hart, D. Hole, P. MacKinnon, C. Gillis, G. Watt, D. Blane, and V. Hawthorne. 1998. Education and occupational social class: which is the more important indicator of mortality risk? Journal of Epidemiology and Community Health 52: 153-190.

Huisman, C. and L. Van Wissen. 1998. Regionale allochtonen prognose 1996-2016, NIDI Report 54, The Hague, The Netherlands, NIDI.

Jarvis, G. K. and H. C. Northcott. 1987. Religion and differences in morbidity and mortality. Social Science and Medicine 25 (7): 813-824.

Joung, I. M. A., J. J. Glerum, F. W. A. Van Poppel, J. W. P. F. Kardaun, and J. P. Mackenbach. 1996. The contribution of specific causes of death to mortality differences by marital status in The Netherlands. European Journal of Public Health 6: 142-149.

Kawachi, I., B. P. Kennedy, V. Gupta, and D. Prothrow-Smith. 1999. Women's status and the health of women and men: a view from the States. Social Science and Medicine 48(1): 21-32. 
Kennedy, B. P., I. Kawachi, and D. Prothrow-Stith. 1996. Income distribution and mortality: cross sectional ecological study of the Robin Hood index in the United States. British Medical Journal 312: 1004-1007.

Kennedy, B. P., I. Kawachi, R. Glass, and D. Prothrow-Stith. 1998. Income distribution, socioeconomic status, and self rated health in the United States: Multilevel analysis. British Medical Journal 317: 917-921.

Mackenbach, J. P., A. E. Kunst, and C. W. N. Looman. 1990. "Regionale verschillen in sterfte aan ischemische hartziekte". Nederlands Tijdschrift voor Geneeskunde 134 (12): 596-601.

Mackenbach, J. P., A. E. Kunst, and C. W. N. Looman. 1991. Cultural and economic determinants of geographical mortality patterns in the Netherlands Journal of Epidemiology and Community Health 45: 231-237.

Mackenbach, J. P. and A. E. Kunst. 1995. "Socio-economic and cultural determinants of regional mortality patterns in the Netherlands". In: A.D. Lopez, G. Caselli, and T. Valkonen (eds.) Adult mortality in developed countries: from description to explanation. Oxford, Clarendon Press, pp.286-303.

Myers, R. H. 1990. Classical and modern regression with applications (2nd edition). Boston, USA, PWS-Kent Publishing Company.

Pampel, F. C. 2001. Gender equality and the sex differential in mortality from accidents in high income nations. Population Research and Policy Review 20: 397-421.

Phillimore, P., A. Beattie, and P. Townsend. 1994. Widening inequality of health in northern England, 1981-91. British Medical Journal 308: 1125-1128.

Pollard, J. 1989. LIFETIME - a WHO/OMS package for analysing survivorship and cause of death. Sydney, Australia, Macquarie University/WHO.

RPD (State Planning Service). 1999. Fertility data (data file requested by NIDI).

Ruwaard, D. (ed.) 1993. Volksgezondheid Toekomst Verkenning: De gezondheidstoestand van de Nederlandse bevolking in de periode 1950-2010. The Hague, the Netherlands, Sdu Uitgeverij.

Sobotka, T., F. Adigüzel. 2002. "Religiosity and spatial demographic differences in the Netherlands" SOM Research Report 02F65, University of Groningen, The Netherlands.

Valkonen, T. and F. W. A. Van Poppel. 1997. The contribution of smoking to sex differences in life expectancy in four Nordic countries and the Netherlands 19701989. European Journal of Public Health 7: 302-310.

Van Poppel, F. W. A. 1992. Religion and health: Catholicism and regional mortality differences in nineteenth-century Netherlands. Social History of Medicine 5(2): 229253.

Van Wersch, S. F. M., H. P. Uniken Venema, and T. W. J. Schulpen. 1997. "De gezondheidstoestand van allochtonen". In: J. P. Mackenbach and H. Verkleij (eds.) Volksgezondheid Toekomst Verkenning 1997; II: Gezondheidsverschillen, Maarssen, the Netherlands, Elsevier/De Tijdstroom, pp.199-223.

Vliegen, M. 1999. "Regionalisation and statistical description". In: J. G. S. J. van Maarseveen and M. B. G. Gircour (eds.) A century of statistics. Counting, accounting and recounting in the Netherlands, Amsterdam, Stichting Beheer IISG, pp.209-240.

Waldron, I. 2000. "Trends in gender differences in mortality: relationships to changing gender differences in behaviour and other causal factors". In: E. Annandale and K. Hunt (eds.) Gender inequalities in health. Buckingham, UK, Open University Press, pp.150-181. 


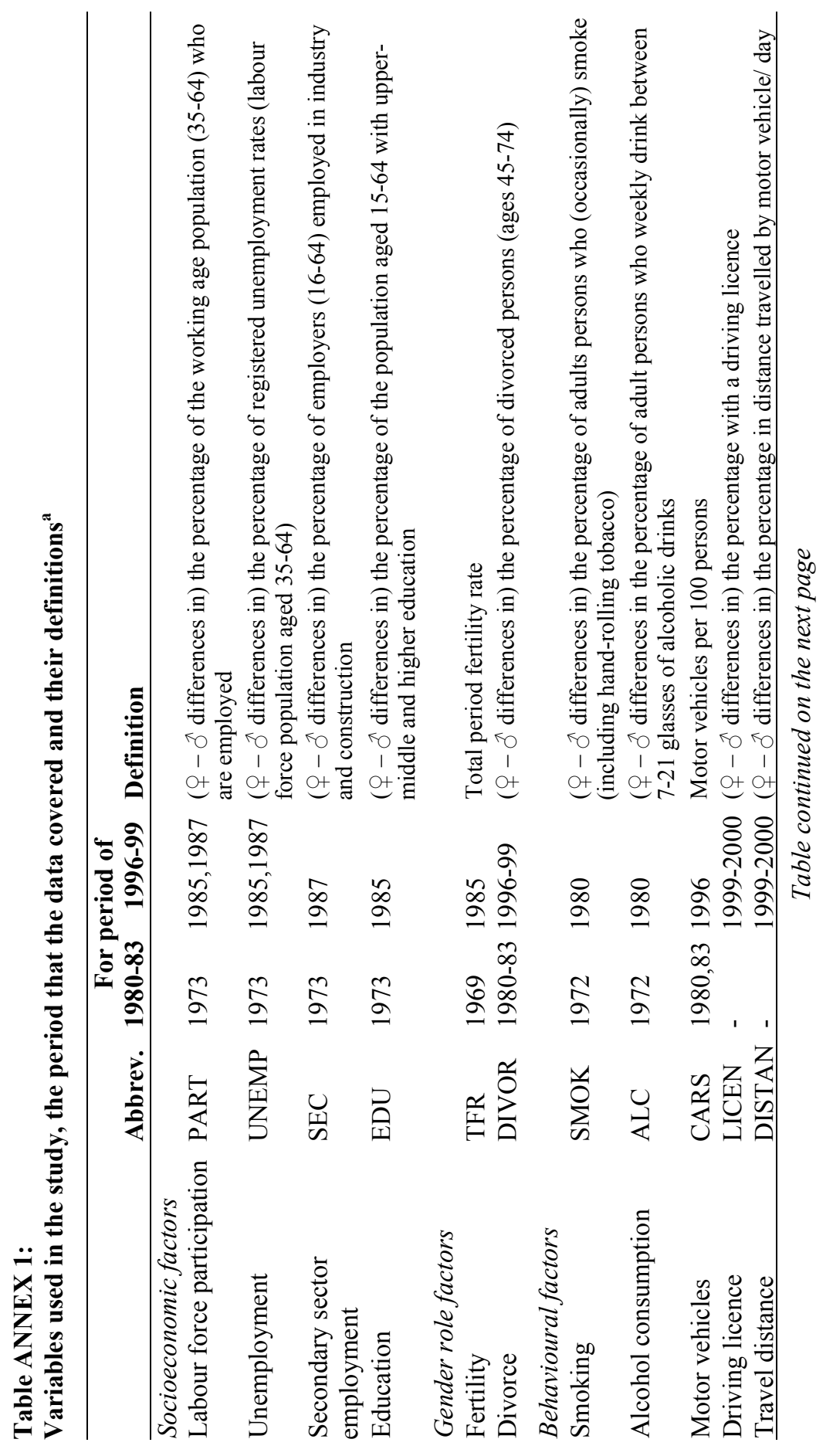




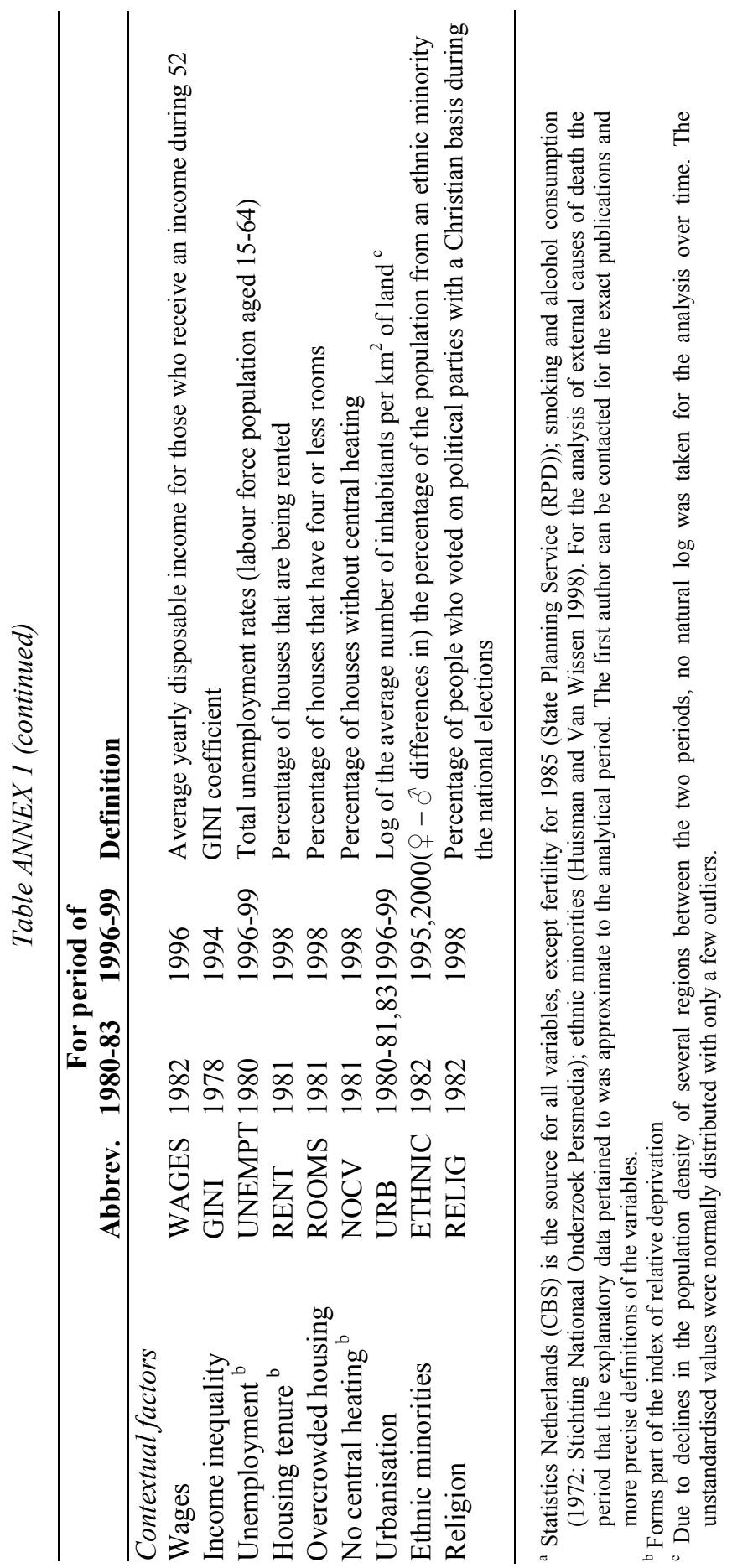


Figure Annex 1:

Absolute number of deaths between ages 45-74 from several causes of death for the period 1990-99
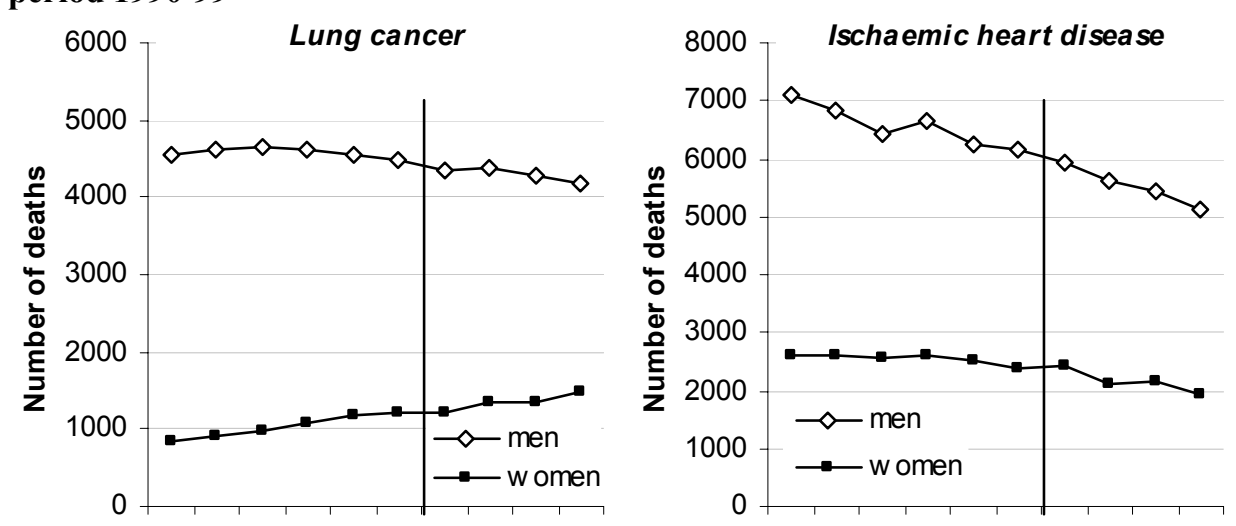

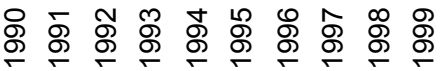

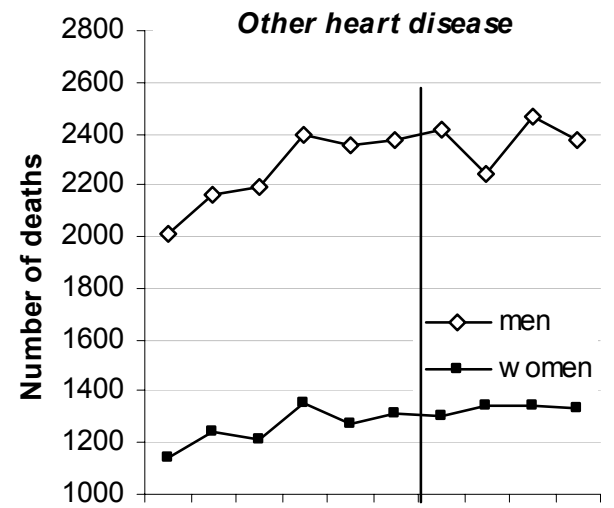

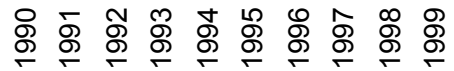

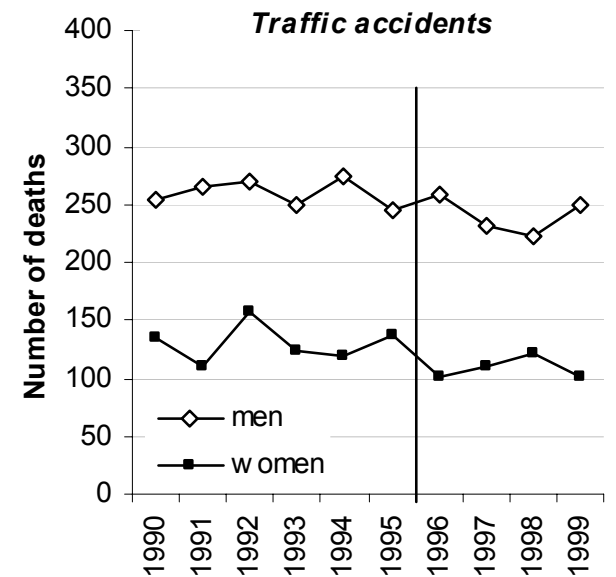

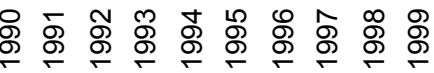
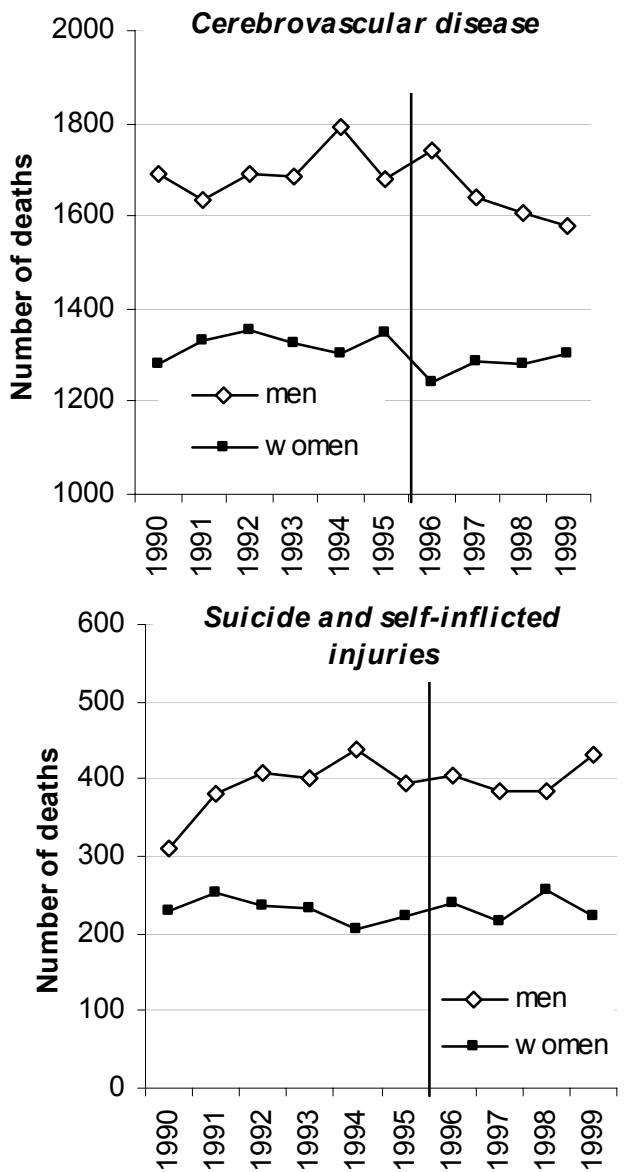
Figure Annex 1 (continued):
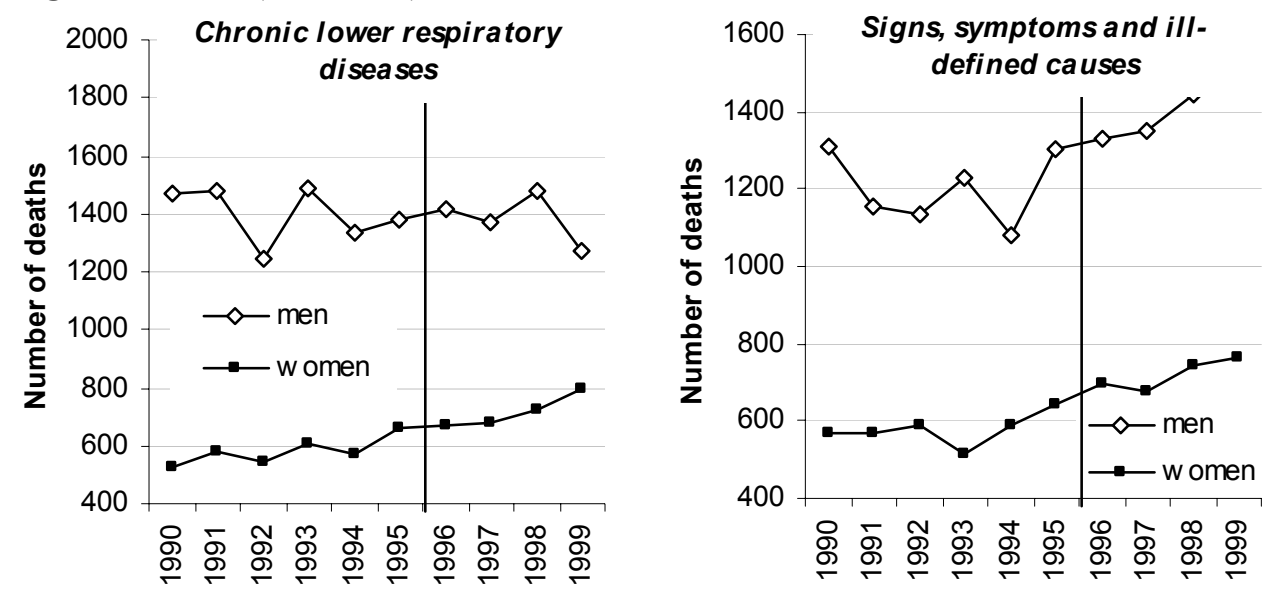